\title{
Synthesis, spectral characterization and crystal structure of a novel trinuclear di-n-butyltin(IV) complex with pyruvic acid- $N(4)$-cyclohexylthiosemicarbazone $\left(\mathrm{H}_{2} \mathrm{PACT}\right)$
}

\author{
M.A. Salam ${ }^{\text {a }}$, M.A. Affan ${ }^{\text {a, }}$, Fasihuddin B. Ahmad ${ }^{\text {a }}$, I. Jusoh ${ }^{\text {a }}$, Mustaffa B. Shamsuddin ${ }^{\text {b }}$, Bohari Yamin ${ }^{\text {, }}$, \\ Yang Farina ${ }^{\mathrm{c}}$
}

${ }^{a}$ Faculty of Resource Science and Technology, Universiti Malaysia Sarawak, 94300 Kota Samarahan, Sarawak, Malaysia

${ }^{\mathrm{b}}$ Department of Chemistry, Universiti Teknology Malaysia, 81310 UTM, Skudai, Johor, Malaysia

' School of Chemical Sciences and Food Technology, Universiti Kebangsaan Malaysia, 43600 UKM, Bangi, Selangor, Malaysia

\section{A R T I C L E I N F O}

\section{Article history:}

Received 27 June 2011

Received in revised form

12 September 2011

Accepted 17 September 2011

\section{Keywords:}

Trinuclear di-n-butyltin(IV) complex

Pyruvic acid-N(4)-

cyclohexylthiosemicarbazone

Spectral analysis

Crystal structure

\begin{abstract}
A B S T R A C T
A new trinuclear di-n-butyltin(IV) complex with pyruvic acid- $N(4)$-cyclohexylthiosemicarbazone $\left(\mathrm{H}_{2} \mathrm{PACT}\right)$ ligand was synthesized and characterized by elemental analyses, molar conductivity, UV-Vis, FT-IR, ${ }^{1} \mathrm{H},{ }^{119} \mathrm{Sn}$ NMR spectroscopy and single crystal X-ray study. Single crystal X-ray diffraction data revealed that this complex was trinuclear cyclic fashion with the pyruvic acid- $N(4)$-cyclohexylthiosemicarbazone ligand. In the trinuclear di-n-butyltin(IV) complex, the ligand $\left(\mathrm{H}_{2} \mathrm{PACT}\right)$ is coordinated to the central tin(IV) atoms via the carboxylato- $\mathrm{O}$, the azomethine- $\mathrm{N}$ and the thiolato-S atoms. The trinuclear tin system is formed by the bridges through the carbonyl oxygen atom of the carboxylate moieties and making the tin atom of seven coordinated in distorted pentagonal bipyramidal geometry. Single crystal X-ray data indicates that the complex (1) crystallized in cubic system with space group $I-4{ }_{3} \mathrm{~d}, a=b=c=30.3273(17) \AA, \alpha=\beta=\gamma=90^{\circ}, Z=16, \mu(\mathrm{MoK} \alpha)=1.209 \mathrm{~mm}^{-1}, F(000)=12,144$, and final $R_{1}=0.0390, w R_{2}=0.0843$ for observed reflections $4582(I>2 \sigma(I))$.
\end{abstract}

(C) 2011 Elsevier B.V. All rights reserved.

\section{Introduction}

Thiosemicarbazones are thiourea derivatives and the studies on their structural and chemical properties have received much attention due to their biological (viz, antibacterial, antiviral and antitumor) activities [1,2]. Organotin(IV) complexes have been extensively studied during recent years mainly because of their potential biological activities (viz, antiviral and antitumor) as well as their wide industrial and agricultural applications [3,4,5,6]. For the past few years, a large amount of work on the synthesis and chracterization of transition metal complexes with thiosemicarbazone have been reported $[7,8,9,10]$ but very little work has been reported on tin(IV) complexes with substituted thiosemicarbazone ligands. The chemistry of polynuclear complexes containing tin or tin mixed with other metal ions has been the subject of much interest in chelate systems [11,12,13]. Recently organotin(IV) macrocycles are attracting more and more attention for their potential industrial applications and biological activities [14,15]. Xu Hao-long (2009) has reported the synthesis and crystal structure of one trinuclear di-n-butyltin(IV) complex with

\footnotetext{
* Corresponding author. Tel.: +60 82583042; fax: +60 82583160.

E-mail addresses: salambpx@yahoo.com (M.A. Salam), maaffan@yahoo.com (M.A. Affan).
}

salicylaldoxime which suggested that the complex is displaying two unequivalent salicylaldoximate with one seven coordinate pentagonal bipyramidal tin atom linked two five coordinate trigonal bipyramidal tin atoms by $\mathrm{Sn}-\mathrm{O}-\mathrm{Sn}$ bridges [16]. In our recent works, we reported the X-ray structure analysis of pyruvic acid- $N(4)-$ cyclohexylthiosemicarbazone ligand and its mono organotin(IV) complex $[17,18]$. As part of our continuous research work on organotin(IV) complexes of $N(4)$-substituted thiosemicarbazone ligands our aim to exploit the versatility of coordination behaviour of organotin(IV) derivatives with pyruvic acid- $N(4)$-cyclohexylthiosemicarbazone ligand. We obtained a trinuclear di- $n$-butyltin(IV) complex of pyruvic acid-N(4)-cyclohexylthiosemicarbazone. Herein, we report the synthesis, spectroscopic characterization and crystal structure of trinuclear di- $n$-butyltin(IV) complex of pyruvic acid- $N(4)$-cyclohexylthiosemicarbazone.

\section{Experimental}

\subsection{Materials and methods}

All reagents were purchased from Fluka, Aldrich and JT Baker. All solvents were purified according to standard procedures [19]. 